\title{
LICENCIATURA X BACHARELADO: O CURRÍCULO DA EDUCAÇÃO FÍSICA COMO UMA ARENA DE LUTA
}

\author{
The Bachelor and Associated Degrees: The curriculum of Physical \\ Education as an arena of struggle
}

\begin{abstract}
RESUMo Como os cursos de Educação Física interpretam as Diretrizes Curriculares Nacionais? Quais práticas discursivas dão base para a elaboração dos currículos dos cursos de licenciatura e bacharelado? Essas são as duas perguntas que orientaram a problematização deste trabalho, e com base nelas foram investigadas cinco instituições privadas na região Centro-Oeste de Minas Gerais que oferecem o referido curso. Levamos em conta que todo currículo deve ser analisado como um espaço perpassado por relações de poder. Além disso, discutimos como as interpretações das Diretrizes são pautadas por relações de poder que dão forma aos currículos, forma adquirida em uma arena social de luta. Para a coleta de dados, utilizamos de pesquisa bibliográfica e entrevistas semiestruturadas e, para problematizar as Diretrizes, trabalhamos com análise documental. Analiticamente falando, na medida em que pesquisamos os históricos das reformas nos cursos de Educação Física, percebemos certa ênfase na estabilidade e na harmonia, não exatamente na mudança. As instituições pesquisadas optaram por manter uma estrutura curricular mais abrangente, sem se definirem claramente por uma das diplomações possíveis: licenciatura e bacharelado (em primeiro momento) e licenciatura e graduação (em segundo momento), não fazendo, assim, alterações e mudanças consideráveis em seus currículos.
\end{abstract}

PalaVRas-ChaVe baCHARELAdO; CURRÍCULO; EDUCAÇÃo FíSICA; LICENCIATURA.

Abstract How do the Physical Education courses interpret the National Curriculum Guidelines? What discursive practices underlie the curricula development for the bachelor and associated degrees? These are the two questions that guided this work, and based on them five private institutions in the Midwest region of Minas Gerais were investigated. We take into account that the whole curriculum should be seen as a space permeated by power relations. In addition, we discuss how the Guidelines's interpretations are underpinned by power relations that shape the curriculum, as acquired in a social arena of struggle. The data collection was performed through literature review and semi-structured interviews and, to discuss the Guidelines, we worked with document analysis. Analytically speaking, while researching the history of educational reforms in Physical Education courses, we noticed a certain emphasis on stability and harmony, not exactly in change. The surveyed institutions have chosen to maintain a more comprehensive curriculum structure, without clearly choosing one of the possible degrees, thus not making considerable changes in their curricula.

KEYWORDS BACHELOR'S DEGREE; CURRICULUM; PHYSICAL EDUCATION; ASSOCIATED DEGREE.

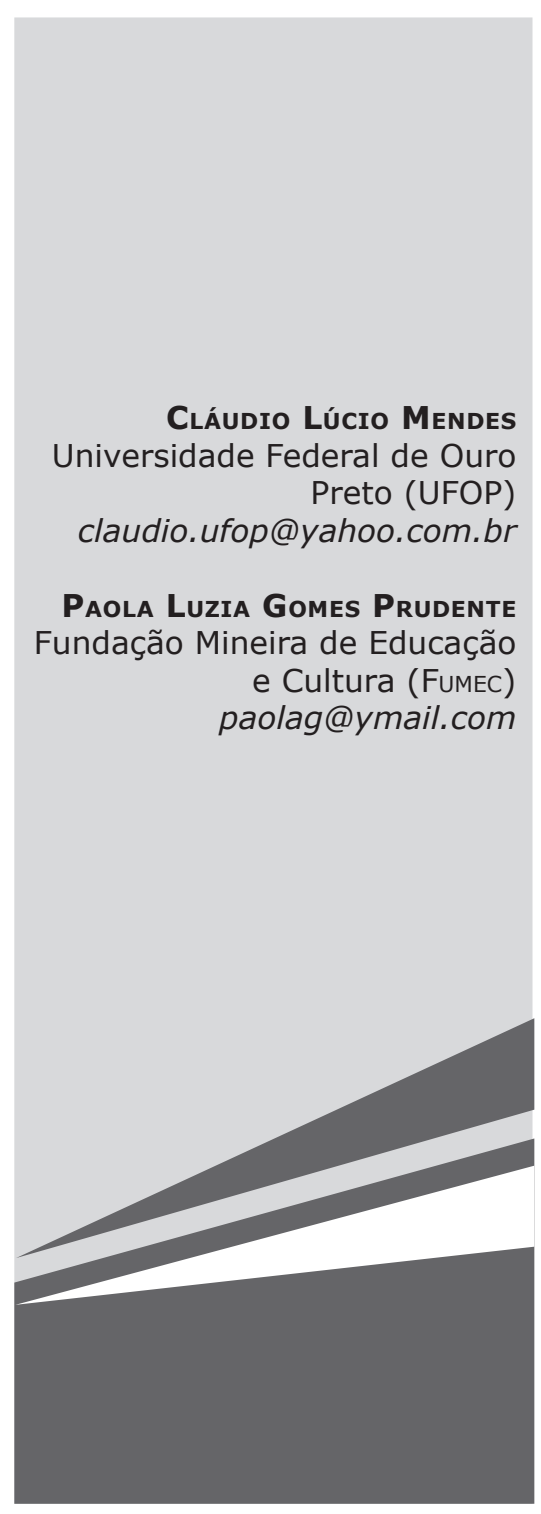




\section{INTRODUÇÃO}

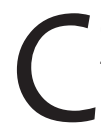
omo os cursos de Educação Física interpretam as Diretrizes Curriculares Nacionais? Quais práticas discursivas dão base para a elaboração dos currículos dos cursos de licenciatura e bacharelado? Essas são as duas perguntas que orientaram a problematização deste trabalho, em razão do qual foram investigadas cinco instituições de ensino superior privadas na região Centro-Oeste de Minas Gerais, Brasil, que oferecem o referido curso. Levamos em conta que todo currículo deve ser analisado como um espaço perpassado por relações de poder, constituídas em momentos sociais específicos que refletem diferentes interesses. Além disso, discutimos como as interpretações das Diretrizes são pautadas por estratégias de poder que dão forma aos currículos, a qual é adquirida em um campo de luta, em uma arena social de luta.

Partimos do princípio de que as reformas educacionais são mecanismos sociais e políticos, entremeados por disputas pela hegemonia de suas práticas discursivas ${ }^{1}$. Assim, arena social é uma possibilidade de explicação do espaço social, em que buscas de diferentes formas de saber são estruturadas e pautadas em distintas relações de poder, construindo, de maneira dinâmica, relações sociais. Ou seja, arena não é um espaço simplesmente ocupado por quem (ou o que) supostamente detém o poder, mas sim é "um espaço onde se viabilizaram (e inviabilizaram) ações políti-

Inspirados em algumas discussões foucautianas (FOUCAULT, 1996, 1997, 2001) e em um de seus comentadores (CASTRO, 2009), empregamos neste texto o termo "prática discursiva". Como Foucault, em vários momentos de sua obra, partimos do princípio de que a linguagem é uma prática - uma prática discursiva - que busca "um modo de abordar a linguagem em sua historicidade, em sua dispersão, em sua materialidade, isto é, sem referi-la nem à sistematicidade formal de uma estrutura, nem à pletora interpretativa do significado" (CASTRO, 2009, p. 251). Preocupamo-nos em descrever e analisar o que o discurso, como uma prática, propõe e produz, e não em sua estrutura formal em termos de enunciados, enunciações, formas, ou mesmo, em seus supostos critérios internos de controle. cas coletivas" 2 , tecendo configurações específicas de conhecimento.

A Lei de Diretrizes e Bases da Educação (LDB) de 1996 trouxe a proposta de serem firmadas diretrizes curriculares básicas, que viessem a interferir em toda a configuração do conhecimento em torno da educação no Brasil. A partir da LDB, especificamente no Ensino Superior, buscou-se a flexibilização na elaboração dos currículos dos cursos de graduação, retirando-lhes as amarras da concentração e a inflexibilidade dos currículos mínimos, propostas pela Lei $n^{\circ} 5 \cdot 540 / 1968$. As Diretrizes Curriculares Nacionais (DCNs) do Conselho Nacional de Educação (CNE) definem as orientações para a organização curricular e institucional dos cursos de graduação plena, bem como, os mecanismos para a avaliação dos cursos a ser realizada pelas instituições formadoras e pelo sistema educacional.

Mais especificamente, para os cursos de Educação Física, duas DCNs distintas balizam a organização curricular: as Diretrizes Curriculares Nacionais para a Formação de Professores da Educação Básica, em nível superior, curso de licenciatura, de graduação plena, (Resolução CNE/CP n 1/2002) e as Diretrizes Curriculares Nacionais para os cursos de graduação em Educação Física, em nível superior de graduação plena (Resolução CNE/CES n 7/2004). Com base nessas Diretrizes, o licenciado em Educação Física deverá ser preparado para atuar como professor da Educação Básica. Já o graduado (antigo bacharel) será formado para atuar no campo não escolar, em lugares como clubes, academias e outros campos que oportunizem práticas de atividades físicas, recreativas e esportivas.

Após essas promulgações, importantes reformulações aconteceram nos currículos dos cursos de Educação Física. Depois da Resolução $C N E / C P n^{\circ} 1 / 2002$, as formações em licenciatura e bacharelado/graduação ${ }^{3}$ não

POPKEWITZ; PEREYRA, 1992, p. 25.

A partir da Resolução CNE/CES n 7/2004, a nomenclatura de bacharelado caiu em desuso, passando a ser chamado de graduação. Mas, durante este trabalho, optamos por utilizar as duas nomenclaturas, da seguinte maneira: bacharelado/graduação. 
poderiam mais ocorrer por meio de um currículo comum (o conhecido $3+1$ ), como acontecia em grande parte das instituições de ensino, desde a Resolução $n^{\circ} 3 / 1987^{4}$. Sendo assim, diante desse quadro colocado a partir de 2002, todas as IES em Educação Física deveriam reestruturar seus currículos tendo como base as novas DCNs.

Cientes do desdobramento citado, acompanhando toda essa discussão há algum tempo - e levando em conta que um currículo se constrói por meio de conflitos, lutas de interesses e posições ${ }^{5}$-, surgiu o nosso interesse pelo tema. Somando-se a tudo isso - trabalhando em IES -, tivemos a oportunidade de participar de algumas discussões informais embasadas nas resoluções CNE/CP n 1/2002 e CNE/CES n ${ }^{\circ}$ 7/2004 sobre esse processo de reestruturação curricular.

Algumas reflexões levantadas nesse período, somadas às teorizações curriculares consultadas, levaram-nos a perceber que não é apenas reestruturando e modificando a composição, a ordem ou a carga horária de uma matriz curricular que se produzirá uma nova mentalidade curricular. É importante compreender o currículo como uma práxis que sofre intervenção de distintas ações, sendo estabelecida no interior de diferentes interações culturais e sociais. Em decorrência dessas inquietações, definimos como objeto de estudo o currículo dos cursos de Educação Física, levando em consideração as normatizações do CNE e as práticas discursivas reorganizadas em torno dessas normatizações.

\section{Metodologia}

Por reconhecer a importância do currículo na formação é que se torna necessário

4 A Resolução $n^{\circ} 3 / 1987$ tratava do "perfil profissiográfico" do licenciado, do bacharel e do técnico desportivo, apresentando uma proposta de currículo mínimo que buscava caracterizar o perfil profissional, definia área de abrangência do currículo e a duração mínima do curso (quatro anos). Indicava também como devia ser a parte de formação geral (Humanista e Técnica) e a parte de Aprofundamento de Conhecimentos Específicos (BORGES, 1996).

5 SILVA, 1999. conhecê-lo. Para tanto, examinamos o currículo dos cursos de Educação Física da região Centro-Oeste de Minas Gerais, por meio de uma análise qualitativa, em um processo que focalizou o contexto da forma mais completa possível. Essa tarefa não é simples, porque não há nada mais complexo que descrever propósitos não explicitados dos comportamentos dos indivíduos e dos papéis das instituições em determinada realidade social e cultural.

Para isso, este estudo - metodologicamente com características de uma pesquisa qualitativa - pretendeu "[...] descrever [...] os fatos e fenômenos [...]"6 da realidade estudada. A pesquisa qualitativa não admite visões isoladas, parceladas, estanques. Ela se transforma em uma "interação dinâmica retroalimentando-se, reformulando-se constantemente, de maneira que, por exemplo, a coleta de dados num instante deixa de ser tal e é análise de dados, em seguida, veículo para nova busca de informações". ${ }^{7}$

Para a coleta de dados, utilizamos de pesquisa bibliográfica e entrevistas semiestruturadas e, para problematizar as DCNs, trabalhamos com análise documental. Ao analisarmos os dados coletados, pudemos apontar incoerências acerca da formação e atuação do profissional, especialmente porque existem aqueles que defendem a separação dos cursos de Educação Física em licenciatura e em bacharelado/graduação e os que a criticam. Mais especificamente, a pesquisa bibliográfica estimulou a busca do referencial teórico para fazer a análise dos dados coletados, por meio de determinadas fontes bibliográficas, com o objetivo de se obter uma compreensão melhor do currículo, das interpretações das DCNs e das relações de poder envolvidas em alguns espaços.

A análise documental serviu tanto para dar informações sobre a técnica de elaboração das entrevistas quanto para a confrontação e a comparação dos dados. Iniciamos pela análise da Resolução CNE/CP n. 1/2002 e da

TRIVIÑOS, 1987, p. 110.

Idem, p. 137. 
Resolução CNE/CES n. 7/2004, bases normativas para a elaboração dos currículos de Educação Física no País. Além disso, levantamos outros documentos que auxiliaram na leitura do cotidiano estudado, como pareceres e resoluções do campo do referido curso, projetos pedagógicos e seus currículos, relatos de experiências e outras fontes cabíveis encontradas nas instituições pesquisadas.

Sem dúvida, os documentos são fontes estáveis, que podem ser consultados várias vezes, constituindo um item valioso na abordagem de dados qualitativos. Em suas diferentes formas, "são ricos em dados que apenas esperam pela atenção dos investigadores", podendo "[...] nos dizer muita coisa sobre os princípios e as normas que regem o comportamento de um grupo e sobre as relações que se estabelecem entre diferentes subgrupos" 9 . No entanto, para meIhor exploração dos documentos e devido à complexidade do problema, também utilizamos entrevistas semiestruturadas.

Tais entrevistas - com durações entre 45 minutos e 1 hora e 30 minutos - foram realizadas nas próprias instituições, com exceção de duas, cujos coordenadores preferiram, por inviabilidade de tempo, marcá-las em outros locais. Elas foram gravadas em áudio e, posteriormente, transcritas na íntegra. Com essas entrevistas, buscamos quais são as interpretações feitas das DCNs (CNE/CP n. 1/2002 e CNE/CES n 7/2004) e quais práticas discursivas são reelaboradas em torno dessas DCNs pelos sujeitos pesquisados, tendo como base um roteiro pré-estabelecido.

Esse tipo de roteiro é um instrumento fundamental quando se tem em vista captar os significados que os sujeitos constroem sobre a sua realidade, pois frequentemente o entrevistado fala livremente sobre o tema proposto. Além disso, possui um caráter de interação muito grande entre o pesquisador e o pesquisado, eliminando a hierarquia existente em outras técnicas de obtenção de

CAMPENHOUDT, 1998, p. 201.

ALVES-MAZZOTTI; GEWANDSZNAJDER, 1998, p. 169. dados. Vale ressaltar que a entrevista permite a "captação imediata e coerente da informação desejada, praticamente com todo tipo de informante e sobre os mais variados tópicos" ${ }^{10}$.

A coleta de dados ocorreu em cinco instituições privadas de Ensino Superior de Educação Física da região Centro-Oeste de Minas Gerais. Faz-se necessária uma análise particular de uma situação ocorrida em uma delas, tendo em vista algumas dificuldades encontradas no momento da entrevista. Em primeiro lugar, ao agendarmos a entrevista por telefone, como vínhamos fazendo com as outras instituições, a coordenadora nos informou que tal entrevista seria liberada se houvesse a participação de uma supervisora para o controle do que seria abordado. Além disso, nos foi pedido o roteiro da entrevista semiestruturada para uma avaliação da diretoria.

Todo o procedimento foi feito, mas, durante a entrevista, na primeira questão, surgiu uma indagação da nossa parte que não constava no roteiro e, como a entrevista era semiestruturada, não víamos problema em questionar algo que seria primordial para futuras reflexões. A supervisora, que a princípio participaria como ouvinte, tomou a frente da situação intervindo com a seguinte frase: "Esta pergunta não consta no roteiro. Nós só responderemos as perguntas que estiverem no roteiro. Você pode se sentir à vontade para reformular o roteiro e passar novamente para a aprovação da direção".

Esclarecemos que era apenas um roteiro de entrevista semiestruturada, que outras questões poderiam surgir ao longo da entrevista, mas ela não concordou a princípio. Continuamos a entrevista com a coordenadora, sempre com interrupções da supervisora. Com o passar do tempo, a supervisora se tornou um pouco mais flexível e passou a responder às perguntas que não constavam no roteiro, e a entrevista foi encerrada sem maiores transtornos.

Para analisar a situação exposta, vamos nos remeter a Foucault (1996) quando nos diz

10 LUDKE; ANDRÉ, 1986, p. 34. 
que as práticas discursivas têm regras sociais e históricas que liberam e ao mesmo tempo restringem as condições de seu funcionamento. Para o autor, não se pode dizer qualquer coisa, em qualquer lugar ou em qualquer tempo. Há regras de uso do discurso. Ninguém entra na ordem do discurso se não satisfizer a certas exigências, ou se não for de início qualificado para fazê-lo, como pôde ser observado durante o caso descrito.

Vale ressaltar que, como procedimento ético e por não ser considerado relevante para o contexto estudado, durante a apresentação e interpretação dos resultados, os nomes das instituições pesquisadas foram preservados, optando-se simplesmente por denominá-las Instituição 1 (I1), Instituição 2 (I2), e assim por diante.

Foram entrevistados os coordenadores dos cursos, identificando quais são suas interpretações sobre as DCNs do CNE nos respectivos cursos, pois, de uma maneira ou de outra, tais interpretações estão presentes nas propostas curriculares. Mesmo sendo cinco instituições, foram entrevistadas seis pessoas, uma delas sendo a supervisora pedagógica já citada.

Dos cinco coordenadores, apenas um era do sexo feminino. O tempo de coordenação deles variava de um a três anos. Todos eram formados em Educação Física, sendo um com a titulação de doutor, dois mestres e dois especialistas. Conforme combinado com os entrevistados, utilizamos uma denominação para as falas, evitando suas identificações. Optamos por simplesmente denominá-los como Coordenador 1 (C1), Coordenador 2 (C2), etc., exceção da referida supervisora pedagógica de uma das instituições, que denominamos Supervisora 1 (S1).

\section{UMA QUESTÃO ANTIGA, NOVOS PROBLEMAS}

A Educação Física brasileira, a partir da década de 90, vem sendo marcada por disputas político-intelectuais, assinaladas por diferentes projetos que propõem caminhos distintos para a formação do profissional. A configuração dos processos de formação estabelecida pelas DCNs do CNE (CNE/CP $\mathrm{n}^{\circ}$ 1/2002 e CNE/CES n 7/2004 - políticas para o Ensino Superior) e a criação do sistema CON$\mathrm{FEF} / \mathrm{CREFs}^{11}$ (que regulamentam a profissão) têm apresentado algumas tendências que vão nortear - e também deixar algumas questões ambíguas - o processo de formação em Educação Física.

Tratando-se especificamente dos debates em relação à polêmica bacharelado/graduação versus licenciatura, encontramos duas vertentes: os que defendem e os que criticam a separação dessas modalidades. Por um lado, para aqueles a defenderem, a separação trará contribuições para a qualificação dos profissionais do campo, ajudando a construir uma produção científica, elevando, assim, o seu reconhecimento na comunidade acadêmica e social, e, por outro lado, aqueles a criticarem, embora reconheçam a fragilidade dos cursos de formação de professores em Educação Física, acreditam que estarão fragmentando ainda mais a formação desses profissionais, promovendo a divisão entre os que produzem e os que transmitem conhecimento ${ }^{12}$.

Note-se que os argumentos de Borges datam de meados da década de 90, nos mostrando que esse assunto não é de hoje. Portanto, tratando-se especificamente dos entrevistados, também encontramos essas duas vertentes, expressas nas práticas discursivas abaixo.

$$
\begin{aligned}
& \text { Se a gente for ver o histórico de } \\
& \text { como foi feito isso, eu sou bem a } \\
& \text { favor de ter essa diferenciação. Mas } \\
& \text { acaba existindo a formação nas duas } \\
& \text { áreas! Acho necessária a regulamen- } \\
& \text { tação de cada modalidade, tendo } \\
& \text { a Universidade a opção de poder } \\
& \text { formar os dois ao mesmo tempo. } \\
& \text { Usar o currículo único, ter disciplinas } \\
& \text { comuns aos dois cursos, e poder for- } \\
& \text { mar os dois ao mesmo tempo }\left(C_{5}\right) \text {. }
\end{aligned}
$$

\footnotetext{
1 O Conselho Federal de Educação Física (CONFEF) e os respectivos Conselhos Regionais de Educação Física (CREFs) foram criados em 1998, pela Lei 9.696, a qual também regulamentou a profissão de Educação Física no Brasil.

12 BORGES, 1995.
} 
Contra. Totalmente contra. Nós não formamos cidadãos diferentes. Nós vamos trabalhar com o mesmo indivíduo. Eu posso trabalhar com o aluno na escola, e depois ele vai para a academia, e eu não posso dar aula para ele? Em um campeonato, eu não posso dirigir a minha equipe porque é uma competição? $\mathrm{O}$ profissional de Educação Física tem duas saídas, o ideal vai ser voltar à licenciatura plena (C4).

Nesse caso específico, mesmo um entrevistado sendo contra e o outro a favor, eles utilizam práticas discursivas similares para justificar os argumentos, sendo a favor das duas modalidades serem contempladas em um único curso, concomitantemente. Ambos defendem a manutenção da licenciatura nos moldes de licenciatura ampliada, de formação generalista. Isso evidencia uma ambiguidade não só nas práticas discursivas descritas, mas também no campo da Educação Física brasileira.

Pesquisas mostram alguns problemas relativos à licenciatura e ao bacharelado (graduação): quando comparamos suas matrizes curriculares notamos que elas são praticamente idênticas, explicitando uma não diferenciação de conteúdos entre as modalidades. Nesse caso, autores propõem que se diferencie realmente uma formação da outra, com currículos e campos de atuações distintos, ou que se faça uma só modalidade, abarcando todos os campos de atuações possíveis na área de Educação Física. De qualquer modo, independentemente da opção seguida, não há muita clareza do que seria a formação em graduação/bacharelado e em licenciatura, não apenas distinguindo essas duas modalidades nos seus possíveis campos de atuação, mas, igualmente, em suas formações ${ }^{13}$.

Discussões mais consistentes sobre a formação em Educação Física são relativamente recentes. No fim da década de 80 e

13 Cf. SOUSA et ali, 1995; BRUGNEROTTO; SIMÕES, 2009; LÜDORF, 2009. durante a década de 90, outros espaços de atuação para o graduado em Educação Física surgiram ou foram requeridos. Nesse caminho, o aparecimento do bacharelado vem preencher essa possível lacuna. Basicamente, a intenção com essa modalidade era garantir maior mercado de trabalho para os formados da área e, concomitantemente, ter legitimidade para além da escola. Entretanto, essas posições não foram suficientes para localizar a licenciatura e o bacharelado nas propostas curriculares, sem conflitos e sem disputas. Grupos de professores não tinham (e nos parece que ainda não têm) clareza do motivo da modalidade de bacharelado (graduação) constar no currículo, principalmente porque não havia diferenciação entre o bacharelado e a licenciatura no currículo de formação, mas, pretensamente, apenas em seus campos de atuação ${ }^{14}$.

Durante essas duas décadas, outras relações de poder puderam ser constatadas, reforçando a presença da modalidade de bacharelado nos currículos. Uma primeira relação de poder referia-se ao discurso oficial expresso pela Resolução n. 3/1987, com grande força de interferência em instituições burocráticas, diretamente ligadas a órgãos centrais de decisão, em especial ao antigo Conselho Federal de Educação. Um segundo fator traduzia-se na possibilidade de garantir um mercado de trabalho mais amplo e assim também reafirmar outros espaços de legitimidade para a Educação Física ${ }^{15}$. Um terceiro ponto caracteriza-se pelo maior status atribuído ao bacharelado, em comparação à licenciatura nas IES em geral, propiciando a oportunidade aos discentes participarem de iniciação científica, e não de estágio de docência, atividade com menor status no meio acadêmico ${ }^{16}$.

\footnotetext{
MENDES, 2005.

MENDES, 1999.

6 MENDES, 2010. No caso da Educação Física, o bacharelado não necessariamente está ligado apenas à pesquisa. Desde as suas discussões iniciais na Educação Física, por um lado, essa modalidade teve uma conotação fortemente de diferenciação no campo de atuação profissional: licenciatura para atuar na docência, no espaço escolar; bacharelado para atuar em todos os outros espaços: academias,
} 
Como já falado, existem posições contrárias em relação à polêmica licenciatura versus graduação/bacharelado. Entre os entrevistados desta pesquisa, isso não foi diferente. Ao contrário dos coordenadores 4 e 5 , os coordenadores 1 e 2 acreditam que a diferenciação deva existir e se pautam nos seguintes argumentos:

Acho que as áreas de atuação são bem diferenciadas. Como as áreas são diferenciadas, a formação também é muito diferente. É claro que as áreas vão se interligar, mas a abordagem é diferente por causa da área de atuação do profissional. Eu acho que só vem a contribuir. $O$ profissional que quiser ser licenciado e bacharel, ele tem esse direito, nada impede que esse profissional tenha as duas modalidades, contanto que ele cumpra todos os objetivos para a formação de um professor e todos os objetivos para a formação de um bacharel (C1).

Eu sou a favor porque os campos de atuação têm que ser bem definidos. Se for licenciatura e está voltada para a escola, a grade curricular tem que estar voltada para isso. Agora você fazer um pouco de cada coisa fica muito superficial (C2).

Nesses dois casos estão presentes alguns aspectos em torno do currículo que exemplificaremos com três questões: quais conhecimentos são válidos para cada modalidade? Que tipo de profissional se pretende

clubes, atividades de alto desempenho, etc. Por outro lado, essas diferenciações sempre foram contestadas e, muitas vezes, colocadas sem sentido ou apenas como uma diferenciação com cunho político e ideológico. Neste trabalho, procuramos evidenciar as ambiguidades e confusões em torno dessas questões nos espaços e currículos pesquisados. Não analisamos a pertinência e aplicação dessas diferenciações em seu sentido de mercado, de atuação profissional, normativo ou legal. formar? Qual é o campo de atuação desse profissional?

Em primeiro lugar, sobre a primeira pergunta (quais conhecimentos são válidos para cada modalidade?), trazemos uma indagação com a qual concordamos:

[...] Admitindo-se que um corpus de conhecimento é concernente com ideias, conceitos, crenças básicas e entendimentos relacionados com um dado objeto de estudo e que a Educação Física teria um corpus próprio de conhecimento, poder-se-ia perguntar se um mesmo corpus de conhecimento poderia formar a base para duas [formações] distintas - licenciatura e bacharelado [/graduação] em Educação Física, ou, contraditoriamente, existiriam dois corpora de conhecimento, um correspondendo à licenciatura e outro ao bacharelado em Educação Física? ${ }^{17}$

Em se tratando dessas inquietações, um dos coordenadores afirma ser necessário "[...] um olhar diferenciado para cada modalidade" (C3). Entretanto, assegura que a "essência" das modalidades é a mesma, sendo o campo de conhecimento idêntico. Sendo assim, idealiza um curso de Educação Física com

[...] entradas únicas, núcleo comum, e um desmembramento ao longo do curso. O que não pode acontecer é você casar essas possibilidades. É você matricular em um curso e obrigatoriamente sair com duas modalidades. A pessoa tem que optar. A área que eu quero é licenciatura, então eu tenho que ter uma especificidade para isso. Não, a área que eu quero é treinamento, então eu tenho que ter uma especificidade para isso (C3).

\footnotetext{
17 FARIA JR., 1987, p. 269, grifo na obra.
} 
Esse curso, a princípio, possuiria um núcleo comum para as duas modalidades e a partir de um determinado período haveria uma mudança de enfoque, buscando caracterizar e diferenciar as modalidades. Contudo, o interessado em obter os dois títulos deveria cumprir a carga horária relativa à distinção das duas. Caso contrário, a formação diferenciada - proposta pelas novas DCNs - seria, conforme seu entendimento, descaracterizada.

Em segundo lugar, vamos nos ater às questões restantes: que tipo de profissional se pretende formar? Qual é o campo de atuação dos profissionais dessas diferentes modalidades? Para iniciarmos essa reflexão, utilizamos uma passagem da entrevista do coordenador 3 .

Hoje temos restrições legais para o graduado/bacharel, ele não tem licença para lecionar. Mas nós não temos restrições para o licenciado. Embora o CREF esteja em uma briga para que seja determinado isso, quem regula é o mercado. Se eu estou licenciado em Educação Física e estou credenciado junto ao conseIho, quer dizer que não tem nada que me impeça de atuar nas duas áreas (C3).

Vale frisar que o argumento em torno da licenciatura vai contra a normatização em vigor apresentada pelo próprio CREF. Ela possibilita duas vertentes de formação distintas para a licenciatura e para o bacharelado/graduação. Portanto, é impreciso divulgar que a licenciatura permita atuar em todos os espaços de intervenção profissional, levando-se em conta as normatizações do sistema CREF/CONFEF.

Ao retomarmos as DCNs, nos deparamos com o curso de formação de professores, sob a orientação da Resolução CNE/CP n. $1 / 2002$, e o curso de bacharelado/graduação em Educação Física, instituído pela Resolução CNE/CES n. 7/2004. Consequentemente podemos destacar que ambos os cursos são em nível superior de graduação plena, que ofere- cem conhecimentos e habilidades distintas, com intervenções específicas e modalidades diferenciadas uma em relação à outra.

Em síntese, até 1998 nos deparávamos com a noção de licenciatura plena, que dava base para o licenciado atuar em todos os espaços de intervenção da Educação Física - ou, pelo menos, não limitava tal atuação ao espaço escolar. A partir de 1998 até 2001, encontrávamos no campo da Educação Física a possibilidade de termos habilitação em licenciatura plena e bacharelado nos moldes do $3+$ 1, oportunizando a formação dos profissionais de Educação Física em curso de graduação, com duração mínima de quatro anos, conferindo o título de licenciado e/ou bacharel.

De 2002 a 2004, a determinação do CNE, por meio da atual legislação, é que existem dois cursos de graduação plena, sendo um de formação de professores/licenciatura e outro de bacharelado/graduação. A palavra plena passou a ser utilizada para toda e qualquer graduação, caracterizando a formação em nível superior, diferenciando-se da graduação sequencial e da graduação tecnológica. Portanto, em relação à aplicação da legislação, é possível constatar que o Parecer $\mathrm{CNE} / \mathrm{CP} \mathrm{n}^{\circ}$ 9/2001 e as Resoluções CNE/CP números 1 e 2 /2002 e CNE/CES nº 7/2004 derrogaram o contido na Resolução CFE n $3 / 1987$, que possibilitava a obtenção de diploma de bacharelado e licenciatura simultaneamente.

O que vem descrito nas Diretrizes é que o licenciado estará habilitado para atuar exclusivamente na Educação Física como componente curricular da Educação Básica, não tendo uma formação orientada para intervir no espaço não-escolar. Em contraste, o bacharel ou graduado estará habilitado para trabalhar em todos os outros campos de intervenção da Educação Física, não tendo formação para atuar como docente da Educação Básica. Em síntese, são duas formações distintas, com intervenções profissionais supostamente separadas.

Outro aspecto relevante, encontrado na fala do coordenador 2, é a nomenclatura utilizada. Ele emprega licenciatura plena, ao invés 
de licenciatura. Nessa instituição, o curso de formação de professores ainda é entendido como um curso de licenciatura plena nos moldes antigos da licenciatura ampliada, caracterizada pelo sentido amplo da palavra plena, dando direito ao graduado de atuar nas duas modalidades de formação em Educação Física - licenciatura e graduação/bacharelado. Essa interpretação fica expressa também em um documento impresso apresentado pelo mesmo coordenador ${ }^{18}$, no qual eram justificados os motivos que levaram à alteração de modalidade do curso - que se iniciou como graduação/ bacharelado e foi alterado para licenciatura.

[...] os graduados em Educação Física no momento atual, e, regionalmente, por um longo tempo, serão impedidos de atuar em escolas estaduais, municipais e outras, se se graduarem, sendo livres para atuarem em outra miríade de mercado de trabalho oferecida. Mas se licenciarem-se, serão livres para atuar tanto nas escolas quanto no restante do campo reservado ao profissional de Educação Física. Isso porque as resoluções do CNE não deixam claras as atuações, senão limitar ao graduado de atuar em Educação Física Escolar. Digo isso porque, pragmaticamente, 0 profissional de Educação Física licenciado não terá restrição para atuar em clubes, academias, escolinhas de esporte, como personal trainer ou tantos outros, como serão limitados os graduandos a exercerem sua função dentro da escola. Além disso, os licenciados têm a possibilidade de se formarem em um prazo atenuado para três anos, em detrimento de cumprirem quatro anos para se gradu-

18 E-mail direcionado a todos os professores, com o resumo de uma das discussões feitas em prol da alteração curricular, justificando a opção por licenciatura em vez de bacharelado. arem. O que faz com que se possibilite a um maior número de alunos a conclusão do Ensino Superior, mesmo tendo em conta possíveis dificuldades financeiras, cronológicas, motivacionais ou outra (C2).

Em relação ao aspecto citado, desde a promulgação da Lei n. 9.394/1996, todos os cursos de licenciatura são de graduação plena, que conduzem o estudante a colar grau e consequentemente receber o diploma de licenciado. O licenciado é aquele que tem licença para lecionar na Educação Básica, como está claramente descrito na normatização vigente. O termo licenciatura plena foi utilizado durante muito tempo para diferenciá-la da licenciatura curta, extinta com a promulgação da Lei n. 9.394/1996.

Portanto, diante desse desdobramento, podemos apontar incoerências acerca da formação e, a partir daí, onde atuará o formado em cada modalidade, haja vista que essa problemática vem sendo denunciada por muitos autores do campo, desde os que defendem a separação dos cursos de Educação Física em licenciatura e bacharelado até os que a criticam. Contudo, não há um pensamento consensual no que se refere à separação ou não das duas modalidades, como pode ser visto nas práticas discursivas dos entrevistados e nas discussões conceituais no campo da Educação Física.

\section{Algumas CONSIDERAÇões}

Quais práticas discursivas dão base para a elaboração dos currículos dos cursos de licenciatura e de bacharelado? Ao longo deste texto, mais especificamente, buscamos responder a essa pergunta. Na educação brasileira, a licenciatura e o bacharelado são abordados por diferentes autores. Eles criticam a atenção dada ao bacharelado - voltado à pesquisa -, deixando a licenciatura em segundo plano. Esse é um problema dos cursos de formação em geral, nos quais a licenciatura aparece com menor status, por trabalhar com o ensino, tendo o bacharelado maior status, por estar orientado à pesquisa. 
Ressaltamos que, apesar de ser uma questão confusa, são poucas as pessoas que realmente se preocupam com isso. Nesse aspecto, cabe salientar que a naturalização desse contexto no campo da Educação Física vem acontecendo com bastante simplicidade, como se os problemas dessa temática já estivessem resolvidos. Entretanto, sabemos que essa discussão sobre o que dá base para os currículos de formação de professores está longe de ser esgotada e, ao repensá-la, obrigatoriamente devemos rever os próprios currículos dos cursos de Educação Física, sempre refletindo que eles (os currículos) têm sido construídos e influenciados pelos contextos produzidos ao longo de suas histórias.

Consequentemente, o atual pensamento curricular do curso de Educação Física no Brasil tem sido influenciado por contribuições de vários campos de conhecimento como o da teoria curricular, formação de professores, política educacional, entre outros. Dentro dessa discussão e considerando o currículo como o centro da atividade educacional, acreditamos que ele se constitua como um campo de conhecimento profundamente engajado nas relações de poder que se manifestam na sociedade. O currículo, sendo o núcleo da relação educativa "[...] corporifica os nexos entre saber, poder e identidade" "19. Como identidade, é um documento que representa um papel fundamental na constituição da subjetividade $^{20}$ de alunos e professores.

Como o currículo nunca é neutro, ele não pode "[...] ser visto como uma listagem de conteúdos planejados para serem cumpridos durante uma determinada etapa do tempo escolar ou somente como uma proposta de grade curricular apresentada pelo poder público”21. Nessas circunstâncias, buscamos

9 SILVA, 1999, p. 10.

20 A noção de subjetividade é aqui entendida como "aquelas conexões que nos ligam a outros humanos, a saberes e a relações de poder que nos rodeiam, constituindo a nós como tipos específicos de sujeitos" (MENDES, 2005, p. 40)

21 MENDES, 2005, p. 39. entender o currículo como um artefato social e cultural, construído historicamente em meio a processos de mudanças e transformações relacionadas às "formas específicas e contingentes de organização da sociedade e da educação" 22 .

É por meio do currículo, concebido como elemento discursivo da política educacional, que os diferentes grupos sociais, especialmente os dominantes, expressam sua visão de mundo, seu projeto social, seus princípios $^{23}$; os mais variados grupos sociais significam suas visões de mundo, suas verdades ${ }^{24}$.

O currículo tem uma posição privilegiada nas reformas, por ser ele o espaço em que se agrupam e se desdobram as divergências em torno dos mais diversos significados sobre o social e sobre o político. O currículo é visto como um dos principais elementos das reestruturações e das reformas educacionais que, em busca de uma eficácia econômica, continuam sendo sugeridas em diversos países ${ }^{25}$

Especialmente no Brasil e no campo da Educação Física, após a promulgação das Diretrizes (CNE/CP n 1/2002 e CNE/CES n 7/2004), as mudanças curriculares têm acontecido para adaptar as IES à legislação vigente. O maior problema por trás dessas mudanças é "como e por que algumas formas de verdade vêm a prevalecer e, em pontos diferentes, são historicamente desafiadas" ${ }^{26}$.

$\mathrm{Na}$ medida em que pesquisamos os históricos das reformas nos cursos de Educação Física, percebemos certa ênfase na estabilidade e na harmonia, e não exatamente na mudança. Apesar de a reforma ocorrida após a Resolução $n^{\circ}$ 3/1987 trazer uma organização curricular mais objetiva e moderna, vanguardista em termos de superação do currículo mínimo, pesquisas de Faria Jr. (1987), Mendes (1999), Gonçalves Jr., Ramos e Machado (2001) e CONFEF (2009) constataram que

\footnotetext{
MOREIRA; SILVA, 1994, p. 8.

3 Cf. MACEDO; ARAÚJO, 2009.

24 SILVA, 1999.

25 SILVA, 2001.

26 POPKEWITZ, 1997, p. 51
} 
muitas IES não fizeram mudanças significativas nos currículos dos seus cursos. As mesmas obras nos mostram que essas instituições optaram por manter uma estrutura curricular mais abrangente, sem se definir claramente por uma das diplomações possíveis: licenciatura e bacharelado (em primeiro momento) e licenciatura e graduação (em segundo momento), não fazendo, assim, alterações e mudanças consideráveis em seus currículos.

Entretanto, apesar de os conceitos de reforma e mudança serem aplicados de modo corriqueiro, com o mesmo significado, não há uma ligação linear entre esses elementos. A pa- lavra reforma "[...] não possui um significado ou definição essencial. Nem tampouco significa progresso [...]"27. As reformas estão direcionadas para uma melhoria na eficiência das formas de ensino que predominam, tornando menos aparentes as formas de regulação social. Nesse sentido, tais formas se relacionam com o poder, na medida em que ele passa a ser exercido sem atos de repressão ou violência, mas por meio da construção de uma identidade social. Esta busca estabilidade e continuidade de acordos institucionais já existentes, construindo processos de controle mais sutis e, muitas vezes, difíceis de serem combatidos.

\section{REFERÊNCIAS}

ALVES-MAZZOTTI, A. J.; GEWANDSZNAJDER, F. O método nas ciências naturais e sociais: pesquisa quantitativa e qualitativa. São Paulo: Pioneira, 1998.

BORGES, C. M. F. Formação e prática pedagógica do professor de educação física: a construção do saber docente. Belo Horizonte, p. 187, 1995. Dissertação (Mestrado Educação) - Faculdade de Educação/UFMG, 1995.

. Formação e prática pedagógica: a construção do saber docente. In: Anais da ANPED, XIX Reunião Anual, Caxambú-MG, set./1996, p. 1-16.

BRUGNEROTTO, F.; SIMÕES, R. Caracterização dos currículos de formação profissional em Educação Física: um enfoque sobre saúde. Physis, Rio de Janeiro, v. 19, n. 1, p. 37-49, 2009.

CAMPENHOUDT, R. Q. L. V. Manual de investigação em ciências sociais. Lisboa: Gradiva, 1998.

CASTRO, Edgardo. Vocabulário de Foucault. Belo Horizonte: Autêntica, 2009.

CONFEF -CONSELHO FEDERAL DE EDUCAÇÃO. O papel do profissional de educação física. Revista E. F., Rio de Janeiro, n. 34, p. 12-19, dez./2009.

FARIA JR., A. G. de. Professor de educação física, licenciado ou generalista. In: MARINHO, V. M. de. (Org.). Fundamentos pedagógicos: educação física 2. Rio de Janeiro: Ao Livro Técnico, 1987, p. 38-57.

FOUCAULT, M. A ordem do discurso. São Paulo: Loyola, 1996.

. Vigiar e punir: nascimento da prisão. Petrópolis: Vozes, 1997.

. Os anormais. São Paulo: Martins Fontes, 2001.

GONÇALVES JUNIOR, L.; RAMOS, G. N. S.; MACHADO, D. F. V. Formação profissional em educação física no Brasil: o velho problema do currículo e o caso da UFSCar. In: Anais do VI Congresso

$27 \quad$ Idem, p. 12. 
Estadual Paulista sobre Formação de Educadores: Formação de Educadores - Desafios e Perspectivas para o Século XXI, 2001, Águas de Lindóia, 2001, p. 1-10.

LÜDORF, S. M. A. Corpo e formação de professores de educação física. Interface, Botucatu, v.13, n.28, p. 99-110, jan./mar. 2009.

LUDKE, M.; ANDRÉ, M. E. D. A. Pesquisa em educação: abordagens qualitativas. São Paulo: EPU, 1986.

MACEDO, E.; ARAÚJO, F. M. B. Notas para uma agenda de pesquisa sobre as arenas burocráticas nas políticas curriculares. Currículo sem Fronteiras, online, v. 9, n. 2, pp. 51-67, jul./dez. 2009.

MENDES, C. L. A reforma curricular do curso de educação física da UFMG: relações de poder, atores e seus discursos. Belo Horizonte, p. 146, 1999. Dissertação (Mestrado em Educação) Faculdade de Educação/UFMG, 1999.

. O campo do currículo e a produção curricular na educação física nos anos 90. Arquivos em movimento. Rio de janeiro, v. 1, n. 2, p. 39-48, jul./dez. 2005.

. Educare UFOP. In: BUARQUE, Virgínia A. C. (Org.). Histórias na cabeça e câmera na mão: uma experiência de ensino através das identidades locais. Ouro Preto: Editora UFOP, 2010, p. 21-32.

MOREIRA, A. F. B.; SILVA, T. T. (Org.). Currículo, cultura e sociedade. São Paulo: Cortez, 1994.

POPKEWITZ, T. S. Reforma educacional: uma política sociológica - poder e conhecimento em educação. Porto Alegre: Artes Médicas, 1997.

POPKEWITZ, T. S.; PEREYRA, M. A. Práticas de reforma na formação de professores em oito países: esboço de uma problemática. In: NÓVOA, A.; POPKEWITZ, T. S. (Org.). Reformas Educativas e Formação de Professores. Lisboa: Educa, 1992, p. 67-102.

SILVA, T. T. Documentos de identidade: uma introdução às teorias do currículo. Belo Horizonte: Autêntica, 1999.

têntica, 2001.

O Currículo como fetiche: a poética e a política do texto curricular. Belo horizonte: Au-

SOUSA, Eustáquia S. et ali. O curso de graduação em educação física: avaliando a formação/ação profissional na UFMG. Belo Horizonte: Faculdade de Educação da UFMG, 1995. (Mimeo.).

TRIVIÑOS, A. N. S. Introdução à pesquisa em ciências sociais: a pesquisa qualitativa em educação. São Paulo: Atlas, 1987.

\section{DADOS DOS AUTORES:}

CLÁUdio LÚCIO MENDES

Universidade Federal de Ouro Preto (UFOP).

Doutor em Educação. Coordenador do Programa de Pós-Graduação em Educação (Mestrado) da UFOP. Coordenador do Núcleo de Estudo e Pesquisa sobre Licenciatura (NEPEL).

Paola luzia Gomes Prudente Universidade FUMEC e Centro Universitário de Belo Horizonte. Mestre em Educação. 